\title{
Letter \\ Guidance in sepsis management: navigating uncharted waters?
} Michael C Reade ${ }^{1}$, Stephen J Warrillow ${ }^{1}$, John A Myburgh² and Rinaldo Bellomo ${ }^{1}$

\author{
1Department of Intensive Care Medicine, Austin Hospital, University of Melbourne, 145 Studley Road, Heidelberg, Victoria 3084, Australia \\ 2Division of Critical Care and Trauma, The George Institute for International Health, PO Box M201 Missenden Road, Sydney, NSW 2050, Australia
}

Corresponding author: Professor Rinaldo Bellomo, rinaldo.bellomo@austin.org.au

Published: 10 October 2008

This article is online at http://ccforum.com/content/12/5/428

(c) 2008 BioMed Central Ltd

Critical Care 2008, 12:428 (doi:10.1186/cc7004)

See related commentary by Vincent and Marshall, http://ccforum.com/content/12/3/162

A platypus is a duck designed by a committee.

(Australian aphorism)

Practice guidelines should be enormously helpful to our patients. We offer another view, however, to that expressed by authors of the Surviving Sepsis Campaign (SSC) [1]. Traditionally, clinical decisions have been informed by peers, but committees such as the SSC seek to drive, rather than reflect, consensus. Is criticism of this new approach justified?

Guidelines can influence physicians to act against their better judgement. For example, while only $47 \%$ of surveyed intensivists believed that central venous pressure should guide resuscitation, $86 \%$ used it because of the SSC recommendation [2]. Protocols may improve care, but what should one do when audited patient outcomes are already better than those achieved by guideline interventions - such as early goal-directed therapy for severe sepsis [3]?

Guidelines for high-income countries may be inappropriate elsewhere, where assigning resources to guideline compliance might preclude other interventions. Such prioritisation is better determined by clinicians in response to local circumstances than by international expert panels. When guidelines become a standard of care, equipoise for confirmatory trials can be lost. Enrolment in the Corticosteroid Therapy of Septic Shock (CORTICUS) trial [4], for example, may have been unsustainably low because corticosteroids had the SSC imprimatur. Guidelines are increasingly used in malpractice litigation despite contrary recommendations. Finally, without the assent of clinicians, inappropriately formulated guidelines risk being ignored.

\section{Figure 1}

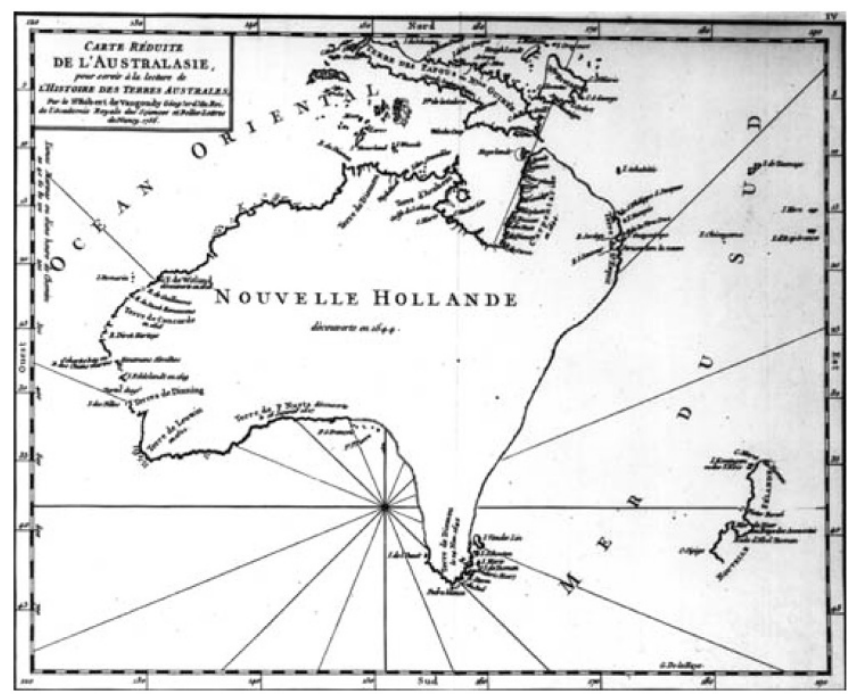

Carte réduite de L'Australasie ("Smaller map of Australia") by Robert Gilles de Vaugondy, published in 1756. More than a list of directions, declaring the unknown as well as the known aids safety and stimulates discovery. National Library of Australia, Canberra, ACT 2600, Australia [http://www.nla.gov.au/ntwkpubs/gw/31/31.html].

We suggest an alternative. Guidelines should define broad goals rather than dictate exact replication of process. For example, instead of recommending rigorous early goaldirected therapy implementation, a guideline could summarise the evidence, and then discuss the merits of approaches (such as fluid therapy, blood transfusion, and inotropic support) targeting central venous oxygen saturation $>70 \%$. Rather than recommending strict glycaemic control, a guideline might discuss the populations in which trials have

CORTICUS = Corticosteroid Therapy of Septic Shock; NICE-SUGAR = Normoglycaemia in Intensive care Evaluation and Survival Using Glucose Algorithm; SSC = Surviving Sepsis Campaign; VISEP = Efficacy of Volume Substitution and Insulin therapy in Severe Sepsis. 
been performed and advise that, pending further evidence, a reasonable strategy might be to control glucose to a degree, but not so intensively as to cause hypoglycaemia. Furthermore, as patrician democracy has given way to universal suffrage, we envisage polls to gain the assent of practising intensivists, such that guidelines reflect true consensus rather than expert opinion. Quality assurance standards - the broadly agreed minimum - should be specifically distinguished from such guidelines.
We sense unease, inside and outside the profession [5], at the list of directions presented by the 'cartographer' experts of the SSC - made more contentious because the geographic features are incompletely known. Our suggestion is analogous to replacing a recommended course with the entire map, marked with areas of certainty and uncertainty (Figure 1). Experience, local conditions, and resources should determine the course of competent practitioners.

\section{Authors' response - A guide to the guide to the guidelines: staying afloat in turbulent seas} John C Marshall and Jean-Louis Vincent

\section{A platypus is a strange-looking animal found only in Australia.}

We appreciate the comments of Reade and colleagues. They underline important points we made: 'Guidelines are not rules and do not preclude the clinician's prerogative to make specific decisions ... that may be inconsistent with general recommendations' and '... the purpose of this guidelines process has never been to constrain those who provide exemplary care' [1]. Moreover, we agree with the importance of garnering the collective diverse views of clinicians; the SSC guidelines involved 55 representatives of 16 different endorsing organisations, and quantified the extent of consensus on the recommendations [6].

We are therefore surprised at the authors' discomfort with the process and the product. Surely Australian intensivists are not so meek they would apply a guideline to the detriment of their patient, and do so because they fear litigation. Nor do guidelines preclude further research. Since the 2004 publication that recommended tight glucose control in sepsis [7], both the Efficacy of Volume Substitution and Insulin therapy in Severe Sepsis (VISEP) trial and the Normoglycaemia in Intensive care Evaluation and Survival Using Glucose Algorithm (NICE-SUGAR) trial have been completed, readdressing that very question. New trials on the efficacy of goal-directed therapy and of activated protein $\mathrm{C}$ are underway. It seems more plausible that guidelines promote high-quality research, by better framing the contemporary question.

Platypuses notwithstanding, there is nothing inexorably unique about the Australian experience. Australian patients could benefit from the collective, often conflicting, and unquestionably imperfect international interpretation of the sepsis literature that informs the SSC guidelines; patients and clinicians around the world would gain more from their engagement in the process of democratic debate than from their sniping from the sidelines. Join us in this initiative, and help to map the future.

\section{Competing interests}

Professor Bellomo is the Principal Investigator in the Australian Government National Health and Medical Research Council funded trial of Early Goal Directed Therapy for patients with severe sepsis, which is soon to commence patient enrolment. In that our article is critical of the guidelines that incorporate this therapy, this could be perceived as an academic conflict of interest.

Jean-Louis Vincent has consulted for Eli Lilly and received honoraria and grant support form the company. John Marshall receives honoraria as a paid member of the Eli Lilly-sponsored PROWESS Shock study, and has served as a paid consultant to other companies with a commercial interest in the development of diagnostics and therapies for severe sepsis and septic shock, including Eisai, Becton-Dickinson, Hutchinson Technologies, and Spectral Diagnostics, and currently serves on data monitoring committees for Leo Pharma and Artisan.

John Marshall is a member of the steering committee of the SSC.

\section{References}

1. Vincent JL, Marshall JC: Surviving sepsis: a guide to the guidelines. Crit Care 2008, 12:162.

2. Li J, Xi XM, Luo X: Analysis of a survey of SSC guideline implemented among Chinese intensivists. Zhongguo Wei Zhong
Bing Ji Jiu Yi Xue 2008, 20:155-158.

3. Ho BC, Bellomo R, McGain F, Jones D, Naka T, Wan L, Braitberg $G$ : The incidence and outcome of septic shock patients in the absence of early-goal directed therapy. Crit Care 2006, 10:R80. 
4. Sprung CL, Annane D, Keh D, Moreno R, Singer M, Freivogel K, Weiss YG, Benbenishty J, Kalenka A, Forst H, Laterre PF, Reinhart K, Cuthbertson BH, Payen D, Briegel J; CORTICUS Study Group: Hydrocortisone therapy for patients with septic shock. N Engl J Med 2008, 358:111-124.

5. Burton TM: New therapy for sepsis infections raises hope but many questions. Wall St J 2008, August 14:A1.

6. Dellinger RP, Levy MM, Carlet JM, Bion J, Parker MM, Jaeschke R, Reinhart K, Angus DC, Brun-Buisson C, Beale R, Calandra T, Dhainaut JF, Gerlach H, Harvey M, Marini JJ, Marshall J, Ranieri M, Ramsay G, Sevransky J, Thompson BT, Townsend S, Vender JS, Zimmerman JL, Vincent JL; International Surviving Sepsis Campaign Guidelines Committee; American Association of CriticalCare Nurses; American College of Chest Physicians; American College of Emergency Physicians; Canadian Critical Care Society; European Society of Clinical Microbiology and Infectious Diseases; European Society of Intensive Care Medicine; European Respiratory Society; International Sepsis Forum; Japanese Association for Acute Medicine; Japanese Society of Intensive Care Medicine; Society of Critical Care Medicine; Society of Hospital Medicine; Surgical Infection Society; World Federation of Societies of Intensive and Critical Care Medicine: Surviving Sepsis Campaign: international guidelines for management of severe sepsis and septic shock: 2008. Crit Care Med 2008, 36:296-327.

7. Dellinger RP, Carlet JM, Masur $\mathrm{H}$, Gerlach $\mathrm{H}$, Calandra $\mathrm{T}$, Cohen J, Gea-Banacloche J, Keh D, Marshall JC, Parker MM, Ramsay G, Zimmerman JL, Vincent JL, Levy MM; Surviving Sepsis Campaign Management Guidelines Committee: Surviving sepsis campaign guidelines for management of severe sepsis and septic shock. Crit Care Med 2004, 32:858-873. 